\title{
Targeting Inequalities: A contribution of the Capability Approach to
}

\section{population studies.}

\section{Claudine Sauvain-Dugerdili}

Institut d'études démographiques et du parcours de vie (I-DEMO), Université de Genève, Claudine.Sauvain@unige.ch

\section{Abstract}

This paper introduces the objectives of the project presented in this Special Issue, i.e. to apply the Capability Approach (CA) to population studies to better understand growing disparities in human development and identify the best indicators to trace inequalities in opportunity. We present here the added value of the CA to population studies, than the characteristics of the two West African countries considered - Ghana and Mali - and, finally, the topics broached. Applying the CA implies a major shift from the classical analysis of the determinants of outcomes to a focus on the array of opportunities and disparities. The eight papers cover three major domains in social demography, especially in West Africa, and for which rich data sets are available: health, seen through risk factors and the spread of obesity; social integration expressed by professional activity and social participation; and family planning viewed in terms of contraception and birth spacing.

Keywords: Capability Approach, Mali, Ghana, population and development

\section{Introduction: targeting inequalities}

This research project grew out of two seemingly paradoxical observations in the population and development fields. On the one hand, we have increasing evidence of considerable achievements in meeting several demographic and health development goals worldwide but with signs of growing disparities between and within populations (Bhutta and Black, 20I3). On the other hand, analysts are being overwhelmed by the mass of new information available to them, but very often these data omit some key measures because of the absence of an underlying theory or even a sense of how social processes interact with economic growth. The papers that follow consider both issues using the Capability Approach a less common framework in population studies that seems to us to address both shortcomings simultaneously.

\section{$>$ Progress engendering increased inequalities}

The Millennium Development Goals (MDGs) reports (United Nations, 2013) highlight that several chosen goals are unlikely to be achieved and that progress is quite unequal between regions and countries, but also within countries. This is evidenced in many instances but most clearly with reference to gender. For example, in North Africa the overall improvement in child survival appears to benefit more to boys, such as shown by the lower decline in female compared to male child mortality (Tabutin et al, 2007). It is increasingly recognized that progress may benefit more the better off so that average measures of achievement may mask growing inequalities (Waage et al, 20l0). This paradoxical association between progress and inequalities, recognized historically during Europe's late 19th century growth (Woods, 2003; Woods, 2000), is most dramatically illustrated in the contemporary world by the case of India (Drèze and Sen, 2013). Recent publications appear to rediscover long standing evidence suggesting that access to innovative advances is often only reachable to a small minority ii. Moreover, it is increasingly recognized that inequalities and social exclusion are persistent and emerging 
issues even in so-called developed countries (UNECE Regional ICPD Beyond 2014 Report ${ }^{i i i}$ ). This new awareness owes much to Wilkinson and Pickett's (2009) cross-country analyses which suggest that societies with a more equal distribution of income have healthier populations and fewer social problems, although confounding factors also play a role. They highlight the pernicious effects of inequality on physical and mental health, drug abuse, education, imprisonment, obesity, social mobility, trust and community life, violence, teenage pregnancies, and child well-being.

As stressed by Drèze and Sen (2013), the lesson to be learned from the Indian case is that economic growth should be accompanied by human development, i.e. ways to enhance human Capabilities. This is the same concept embodied in the reaffirmation of the commitments to the International Conference on Population and Development (ICPD) paradigm that encourages "investing in the development of people, in particular women and vulnerable groups, so that individual men and women are in a position to take decisions and make choices that would enable them to achieve a higher state of well-being" (UNECE beyond 2014).

\section{$>$ A plethora of data collection but poor measurements}

With the legitimate aim of measuring tangible progress rather than just virtuous wishes, the MDG framework produced a variety of quantitative targets. Although laudable, this has proved problematic in at least two ways.

First, it has generated an impressive data collection industry supported by governments, non-governmental organizations and civil society. The rich, standardized data sets beginning with the World Fertility Survey and continuing with the Demographic and Health Surveys have been supplemented by studies by other UN agencies (the World Bank's Living Standards Measurement Surveys and UNICEF's Multiple Indicator Cluster Surveys). These data sets are widely used to quantify progress towards the MDGs as well as setting priorities for investment in population, reproductive and sexual health services. Many international efforts to provide evidence of demographic and social change especially in data-poor, low income countries, have uncovered new features of the demographic and health transitions not seen in Europe and North America. Nonetheless, as witnessed in the Mali and the Ghana cases discussed here, this explosion in data collection is supported by foreign agencies anxious to measure progress in the indicators of most concern to their own programmes. Thus a parallel system developed, often out of the control of the national institution in charge of data collection.

Second, these data are generally used to produce indicators of average achievements in specific sectors or sub-sectors, allowing comparison across countries and assessment of achievement in quite narrow domains. In most cases, the information collected does not meet planning needs at the local level and data are under-utilized within the countries themselves. Clearly, observations of the trends in achieved levels in fertility, in education, in child mortality and other measures of social development do not themselves provide indicators of the most effective pathways for actions aimed at reducing inequalities for even the narrowest targets such as school enrolment or contraceptive prevalence, and thus may miss the more central human development goal of improving education or enabling women to plan their family (Yamin and Boulanger, 2013).

The challenge taken up here is to show that in spite of their limitations, the data collected could be re-analysed and re-interpreted to help in understanding the sources of inequalities or, as highlighted by Waage et al (2010), the more basic human development needs.

\section{The Capability Approach: a tool to explore the drivers of inequalities in opportunities}

This research project takes the Capability Approach (CA) to apply it in population studies in order to better understand the deeper, 
underlying determinants of the differentials in demographic behaviour and related human development. By focusing on people's "freedom to achieve", the CA considers the multiple dimensions of poverty, the causes of inequalities in well-being, people's real deprivation, as well as differences in needs. It concentrates on equity in opportunities rather than end points such as equality, degrees of satisfaction and dissatisfaction. The CA was conceived as a theory extending beyond economic approaches based on income measures, human capital indices, utility or possession of primary goods (see previous paper). It focuses on the real situation of people, on the reason why they have an unequal ability to make use of the resources theoretically available to them. Human development is thus seen as a "process of expansion of the real freedoms that people enjoy"; in other terms, a series of Capabilities that make them able "to live the life they have reason to value" (Sen, 1999).

As recalled in the first paper, the philosophy of the ICPD Program of Action, the so-called Cairo paradigm, shares the basic principles of the CA. $\mathrm{CA}$ is convergent with current thinking in social demography that accounts for inequalities and for intentions and decision making. The context of the individualization of behaviour is at the heart of the theory of the Second Demographic Transition (Van De Kaa, 1994; Lesthaeghe, 1995). Refined analyses of individual differential own much to the development of analytical tools to consider the life course perspective and further broadened to consider the person's “entourage" (Bonvalet et Lelièvre, dir, 2012; Basu, 2013), or to distinguish between different levels of determinants by applying multi-level analyses (Courgeau, 2007), while mixed methods approaches aim to account for differing people's viewpoints. Explanatory models of intentions and decisionmaking are considered by applying agent-based models in demography (Billari and FürnkranzPrskawetz, 2003) and linking to cognate theories developed in psychology or sociology such as the Planned Behaviour model (Ajzen 1988; Billari et al, 2005), or the social production function
(Lindenberg, 1996).

The CA does not offer new tools but provides a framework with organizing concepts that emphasize the process and not simply the outcomes. By focusing on people's real opportunities, agency - what enables people to expand them - becomes a central issue in the analysis of inequalities in well-being. We consider here individual agency directly in accounting for the person's viewpoint in the qualitative surveys and indirectly as a cross-cutting dimension introduced through the examination of differentials at two levels:

I) Differentials in individual access and use of resources observed by distinguishing inequalities in availability and quality of contextual resources (including services) from inequalities in personal resources that restrict or enhance individual capacity to access and use them.

2) Differentials in the ways individuals cope with life hazards as well as in people's motivations and goals through the examination of the dyad Capabilities/functionings, i.e. the gap between opportunities, in other terms the freedom to achieve and the outcome, i.e. the achievement. In particular, how do people manage in situations of high uncertainty and how do they cope within the institutional framework of constraining norms?

Thus, agency is not seen as the actions of a person disconnected from his or her context but following Emirbayer and Mische (1998), as a "temporally embedded process of social engagement", or as "situated" projects (Bassand et al, 1975).

\section{Ghana and Mali: two countries in the same sub-region, but with contrasting demographic and socio-economic dynamics}

The project took place in two West African countries primarily because the principal investigators including the national researchers had many years of prior research experience on population and health issues. Nonetheless, West Africa appears especially appropriate due to the complex syncretism between long established 
traditions and indigenous socio-cultural frameworks and the rapid trends in modernization and globalization. Ghana and Mali provide two contrasting cases although located in the same geographical area and sharing many socio-cultural characteristics, such as long- standing traditions of extended birth spacing. Their distinct colonial histories and different rates of recent socio-economic development place them at opposite ends of the development spectrum within the sub-region (Table I).

\section{Table I. Demographic and socio-economic dynamics in Ghana and Mali.}

\begin{tabular}{|c|c|c|c|c|}
\hline & $1950-55$ & $1980-85 / 1980$ & $2000-05 / 2000$ & $2005-10 / 2012$ \\
\hline \multicolumn{5}{|l|}{ Ghana } \\
\hline *Fertility rate (live births per woman) & 6.4 & 6.4 & 4,6 & 4.2 \\
\hline "Adolescent fertility rate (births per 1,000 women 15-19y.) & 149.0 & 128.3 & 77.0 & 67.6 \\
\hline *Infant mortality rate (per 1,000 live births) & 147 & 93 & 61 & 55 \\
\hline "Life expectancy at birth (years) & 42.2 & 53.0 & 57.5 & 60.0 \\
\hline *Percentage urban & 15.4 & 31.2 & 44 & 51.2 \\
\hline ***Human Deve lopment Index (HDI) value & & 0.391 & 0.461 & 0.558 \\
\hline *.*Mean years of schooling (of aduits) (years) & & 3.6 & 6.3 & 7 \\
\hline ***GNI per capita in PPP terms (constant 2005 internat \$) & & 984 & 1,037 & 1,684 \\
\hline \multicolumn{5}{|l|}{ Mali } \\
\hline "Fertility rate (live births per woman) & 6.5 & 7.1 & 6.8 & 6.8 \\
\hline -Adolescent fertility rate (birthis per 1,000 women 15-19y.) & 187.7 & 189.9 & 185.1 & 180,9 \\
\hline *Infant mortality rate (per 1,000 live births) & 242 & 151 & 109 & 100 \\
\hline "Life expectancy at birth (years) & 27.0 & 41.6 & 50.3 & 52.7 \\
\hline **percentage urban & 8.5 & 18.5 & 28.1 & 34.3 \\
\hline${ }^{* * *}$ Human Deve lopment Index (HDI) value & & 0.176 & 0.27 & 0.344 \\
\hline ***Mean years of schooling (of aduits) (years) & & 0,4 & 1.2 & 2 \\
\hline ***GNI per capita in PPP terms (constant 2005 internat \$) & & 737 & 744 & 853 \\
\hline \multicolumn{5}{|l|}{ Sources: } \\
\hline \multicolumn{5}{|c|}{ *World Population Prospects, Population Division, United Nations, 2012 revision,http://esa.un.org/unpd/wpp/. } \\
\hline \multicolumn{5}{|c|}{$\begin{array}{l}\because \text { World urbanization prospect, } 2011 \text { revision, http://esa.un.org/unpd/wup/index.htm } \\
* \text { * Inter national Human Development Indicators, http://hdrstats.undp.org/en/tables/. Data for } 1980,2000,2012\end{array}$} \\
\hline
\end{tabular}

The two countries have experienced significant progress in life expectancy, particularly through a decline in infant mortality. The latter's levels remain however high and, in Mali, there has been little progress in recent years. Mali is also still much more rural and has witnessed severe inequalities in socio-economic improvement. The disadvantage is especially high in schooling and in GNI per capita. In 2012, Mali ranks 182 over 187 In the Human Development Index, while Ghana ranks 135, making it the leader in the sub-region. The Multi-Dimensional Poverty Indexiv is four times more in Mali (56\% versus 14\%, Human Development Report, 20I3). Mali and Ghana are characterized by low levels of contraceptive prevalence despite family policies that were first established more than forty years ago in Ghana (1969) and more than twenty years ago in Mali (1991). The last DHS surveys show that in Mali, the contraceptive prevalence rate is still below 10 per cent and, in Ghana, it has been stagnant at slightly more than 20 per cent for two decades. The demographic dynamics in both countries are also quite different. While both had total fertility rates close to seven until around 1975, this rate has declined considerably in Ghana since then, down to less than five by around 2000, whereas in Mali, it has stayed at around 6.5 (Table I). In both countries, fertility has dropped considerably in the capital city, but in varying degrees: down to 2.5 births in Greater Accra (DHS 2008) but only 4.8 births in Bamako 
(DHS 2006).

Most of all, the two countries differ strongly in regard to the position of women, as expressed in marriage patterns and in opinions about gender issues (Locoh, 20I3). Early marriage remains the rule in Mali while it has considerably decreased in Ghana: $71 \%$ of women are married before 18 years in Mali (EDS, 2006), just $25 \%$ in Ghana (DHS, 2008). The age gap between spouses has remained stable since the 1990s, around 6 years in Ghana and, in Mali, around 9 years in rural areas, while in urban settings postponement of men's marriage led it to increase to 12. The proportion of women in polygamous unions has considerably decreased in Ghana, much less in Mali, especially in rural area: In the Ghana 2008 DHS, $81 \%$ of women $15-49$ years are reported as monogamous, $93 \%$ in Greater Accra and $95 \%$ among those with secondary plus schooling, the same indicators being in Mali $60 \%, 76 \%$ in Bamako and $81 \%$ among the more educated ones. In Mali, $75.2 \%$ of women agree that the husband may beat his wife ${ }^{v}$ and only $27.3 \%$ declare that a woman can refuse sexual intercourse when tired or not in mood; for Ghana, the figures are $36.6 \%$ and $82.5 \%$.

\section{A multidisciplinary, multicultural research project applying the CA to secondary analysis of existing data}

The project was developed and implemented by a consortium comprising the Institute of Demographic and Life course Studies (I-Demo), University of Geneva, and the Harvard Center for Population and Development Studies (Cambridge, USA), their partners in Bamako (Faculty of Medicine, University of Mali, and the Direction nationale de la population) and in Accra (Department of Geography, the Ghana School of Public Health and the Regional Institute of Population Studies, University of Ghana), with the collaboration of the Department of Political and Social Science at the University of Pavia (Italy) (Box I).

\section{Box I. Research Teams.}

'Enhancing the Capabilities of the most vulnerable in West Africa'.

Bamako : Prof. Samba Diop; Dr Sory lbrahima Diawara, Samba Diarra, Dept de santé publique, Faculté Médecine / Contribution de la Direction Nationale de la Population, Ministère économie.

Accra : Profs. Samuel Agyei-Mensah \& John K. Anarfi; Adu O.Sarkodie, Thomas Antwi Bosiakoh et Faustina Frempong (in Southampton), Dpt Geography \& Regional Institute Population Studies, University of Ghana.

Genève : Prof Claudine Sauvain-Dugerdil ; Mathias Lerch, Ababacar Dieng \& Anouk Piraut; IDEMO, Université de Genève.

Harvard : Prof Allan G.Hill (currently at the University of Southampton); Nelly Douptcheva (in Geneva), Harvard School of Public Health.

Pavia : Prof. Enrica Chiappero-Martinetti: Nadia Von Jakobi \& Lia Quartapelle, Dpt of Political and Social Science, University of Pavia and the Human Development, Capability and Poverty International Research Centre, Institute for Advanced Study, Pavia (Italy)

Two Capability key persons joined the team to contribute to events organized by the project: Prof. Sridhar Venkatapuram, King's College London, at the round table organized at the IUSSP Conference in Busan (August 2013), and Dr. Kevin Lompo, UMI-Résiliences from IRD Paris-Nord, at the Bamako workshop (December 2013). 
The main aim of the project was to apply the CA as a new conceptual and methodological approach to the analysis of changing demographic behaviour and its consequences in terms of inequalities in well-being. One key issue was to ascertain whether the capability framework can lead to a fuller exploitation of existing survey data. The project has therefore developed a methodology for the secondary analyses of survey data not originally collected with the CA framework in mind. Analyses have been carried on two types of data. First, we use the rich material collected by the initiators of the project, i.e. the survey "Chantier Jeunes" on the transition to adulthood in Mali (see chapters 4 and 7) and a large-scale survey conducted by the teams researching women's health in Accra (chapter 3). Secondly, we conducted some secondary analyses of larger national surveys including the Ghana Living Standard Survey (chapter 6) and, in both countries, the most recent Demographic and Health Surveys (chapters 5, 8 and 9). In addition, ad hoc qualitative surveys were carried out to explore some of the factors associated with the notions of choice and preference (chapters 5 and 10).

Applying the CA implies a major shift away from the classical analysis of the determinants of outcomes (in the present topics: fertility level, morbidity, occupation, contraceptive prevalence) to a focus on the array of opportunities and gaps, that is to say "people's freedoms to be and do what they have reason to value". We chose to work on seven topics from three major domains in social demography, especially pertinent in West Africa, and for which rich data sets are available:

- Health seen through the lens of risk factors and of obesity;

- Social integration seen through professional activity and social participation;

- Family planning seen through contraception and birth spacing.

These three domains encompass a series of Capabilities from Nussbaum's list (Nussbaum, 2000). Most aspects that she includes in Bodily Health, i.e. "being able to have good health, including reproductive health; to be adequately nourished".

Other dimensions are covered by what Nussbaum refers to as:

Senses, Imagination, and Thought. "Being able to use the senses, to imagine, to think, and to reason-and to do these things in a 'truly human' way, a way informed and cultivated by an adequate education [...]. Being able to use imagination and thought in connection with experiencing and producing works and events of one's own choice [...]"

Affiliation. "Being able to live with and toward others, [...] to engage in various forms of social interaction."

Practical Reason accounts for issues of individual agency, expressed as "being able to form a conception of the good and to engage in critical reflection about the planning of one's life." Each study developes an analytical framework from a capability viewpoint, but specific to the context and issues at stake. All refer to a common basic schema (Figure I adapted from the more general one given in the first paper of this issue) and to common definitions. Each case study conceptualizes the dyad Capabilities/Functionings - that is to say, distinguishing the range of opportunities from the real achievements - as well as the different sources of inequalities and identifies the best proxies or possible composite indicators to be constructed from the available data (variable mapping). 
Figure I. The Capability Framework

(adapted from Robeyns $2005^{\mathrm{vi}}$ and Chiappero \& Venkatapuram in this volume)

\section{Endowments}

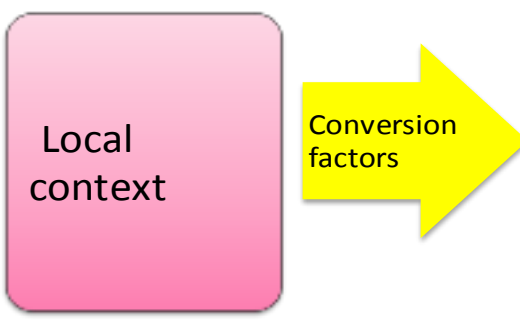

Means to achieve

$$
\text { Capability set }
$$

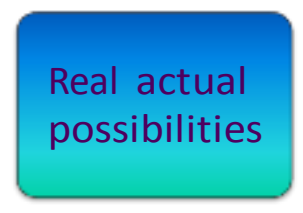

Selection / preference

\section{Functioning set}

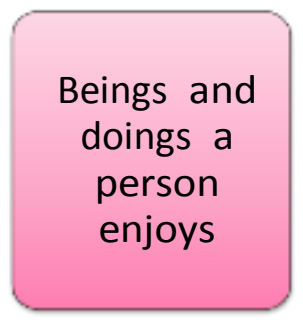

Achievement

Freedom to achieve

The application of the CA thus implies a two sided strategy:

a) considering the Capabilities as a perspective to choose the best proxies to measure well-being, seen as a process;

b) identifying the various sources of inequalities both for capabilities and functionings.

\section{A. Capabilities and functionings: the multi- dimensional nature of the quality of life from the viewpoint of the person.}

By considering the achievement as the outcome sorted from an array of actual opportunities, the CA concentrates on the process of generating well-being. The CA contributes therefore to the long lasting debate about the definition and measurement of the quality of life in at least two ways. First, the distinction between opportunities and outcome provides a framework for grasping the multi-dimensional nature of well-being and its determinants. Second, the role of individual agency occupies a position of central importance. This implies the need for subjective measurements to account for the individual viewpoint and for documented factors of inequalities in individual ability to access and use the available resources.
The main challenge in applying the CA to demographic analysis is to identify proxies that can be used to describe adequately the Capabilities. By definition, the space of opportunities cannot be fully measured. The information available will never provide a comprehensive description of the entire array of possibilities. Moreover, these change over time and the "freedom to achieve" arises from viewpoint of the perception of the person involved. Econometric models introduce Capabilities through latent variables which we consider unsatisfactory because their exact meanings are often difficult to interpret. In the present project, each study has identified the best proxies among available variables to quantify well-being - here referring to health, social integration and family planning - in terms of the ability to being and doing well in these life domains and of the reasons why people enjoying apparently the same conditions end up with differences in well-being.

* The "ability to enjoy good health" has been the subject of enquiry through selfreported health questions addressed to Accra women and to young people in Bamako. In the Accra study, the Capabilities are considered 
through the dispersion of the health indexes in this population. In the Bamako case, we test whether the use of health services constitutes a Capability, that is to say, that these young people are "effectively able to access quality healthcare" having the conviction that it will improve their health state. As regards obesity, the Capability framework offers a very useful way to detangle the different types of risk factors by using mixed quantitative-qualitative methods to go beyond usual health centered approach to understand the meanings that people give to obesity in the specific context of Ghana and Mali.

\section{* Social participation and professional} activity are seen as Capabilities in the domain of societal integration in the sense of the ability to use knowledge, skills and networking to "live the life one has reason to value". In other words we consider people's control over their lives through the role of education in opening the way to secure occupation. Two other studies analyze the role of social participation, on the one hand, on women conciliation of employment and large families and, on the other hand, on individual freedom expressed by unstructured time.

\section{* The study "Shaping the Family" offers an} alternative to the classic studies on the determinants of fertility and the number of overly simplistic views of a causal relationship between contraceptive use and realized family size. Through a secondary analysis of DHS data and a qualitative survey, we explore women ability to "have good reproductive health", that is to say the reasons why some women are able to manage the construction of their family and others not. We proceed in two steps. First, we examine whether contraceptive knowledge opens up the opportunity to control realized fertility through the use of contraception. In a second step, we test whether those persons who adopt modern contraception are able to plan their family effectively, as expressed by birth spacing. The qualitative data are used to discuss the respective roles of cultural norms, in particular long-standing traditions of birth spacing, and new more individual behaviour reliant on differences in personal resources.

\section{B. Means to achieve: different sources of inequality}

The unequal ability to "live the life one has reason to value" results from the availability and accessibility of different kinds of resources but also from the ability and willingness to use them for one's own sake. The CA frames the analysis by making a fundamental distinction between endowments and so-called conversion factors. It further distinguishes between personal, family and societal resources, as well as between those resources that are fixed and/or stable and those that evolve along with life experience. In population issues, the Capability framework constitutes a tool to structure the analysis of heterogeneity and revisit the distinction between offer and demand factors.

In the present studies, we make use of usual socio-demographic tools. We have built probabilistic models (regression analysis) to consider the factors of variability of the proxies for Capabilities, which in a second step become themselves explanatory factors of the achievement. This has been chosen as an alternative way to a path analysis which allows more flexibility in the analysis of heterogeneity. Globally, we proceeded in testing first the effect of the environment resources and, in a second step, introducing individual characteristics to test both their own effect and whether they modify the context effect. The aim is to highlight factors of vulnerability shared by specific groups of people, especially distinguishing the offer side that is to say resources of the context, in particular services - from the demand side expressed by differences resulting from individual characteristics and position towards values. The main issue at stake is thus whether personal resources can buffer the impact of poor surroundings (see in particular chapter 3 ).

The eight papers presented hereafter (chapters 3 to 10 ) illustrate well that the CA is providing a global guideline for framing the research question and structuring the analysis, but that its 
precise implementation, and the identification of the proxies, rely on the issue at sake and, when proceeding to secondary analysis, on the information available.

The resources of the context are used as proxies for collective endowments. In the Mali and Ghana context, the place of residence (urban or rural, type of sector in town) is a valuable indication of resources available and degree of sanitation, and can thus be used as a proxy, but of course it would be better to have more accurate information about real life conditions and services such as introduced in some of the studies (see in particular chapter 8).

As regards individual characteristics - among which we also include those of the household and of socio-cultural belonging - the Capability framework distinguishes acquired personal resources from fixed endowment, that is to say personal resources that can be boosted from those that cannot be modified. The consequences that the latter have on well-being may however differ with the characteristics of the context and their social meanings. Such is the case of two central variables in demography, age and gender, which constitute basic individual endowments that carry inequalities through their specific socio-cultural meanings and its consequences in terms of unequal individual agency. Whenever the information is available, the analyses also account for the specificities associated with the stages in the life course, in particular life transitions such as parenthood or entry into the labour market, or life history for instance the effect of past health history (chapters 3 and 4).

In all studies, a central issue is the respective roles of human and economic resources. Whenever available, information on education infrastructures in the sector of residence is taken in account as an environment resource, while in chapter 7 achieved schooling is considered as an individual endowment, and in other studies, its net effect, after controlling for economic level, as a mean to use the resources (conversion factors). The household wealth - an information available in all data sets used here - is interpreted in the papers of the colleagues from economy and public health as a resource, whereas sociodemographic analysis considers it rather as a means to access and use the context

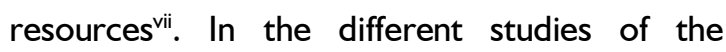
present project, occupation has been considered either as an accomplishment - i.e. type of occupation, job security as an indicator of quality of life - or as a Capability, a proxy for the ability to have control over life, but also as a conversion factor, a means to achieve other dimensions of well-being.

\section{A publication in three sections}

The main aim of this Supplement is thus to provide illustrations of the application of the CA to secondary analysis of data not collected with the CA in view. Through seven studies in three domains using different types of data by researchers from different disciplines and institutions, it renders a sample of the diversity of the application of the CA in sociodemographic analysis. These studies are put in perspective through the present introductory section and a final discussion. The final chapter will summarize the main outcomes and lessons learned from the project. It will discuss the strengths and weaknesses of the CA, its contribution to population studies and also how future socio-demographic analyses might circumvent some of its weaknesses. We shall return to the challenge of targeting inequalities in scientific research and in policies and programmes by discussing the topics that need further studies to better understand the sources of inequalities, and the best indicators for monitoring and evaluation of actions.

\section{References}

Bassand, Michel, Jean Kellerhals et Geneviève Wirth (1975), Familles urbaines et fécondité. Librairie de l'Université de Genéve.

Basu, K. (2013), Group identity, productivity and well-being: policy implications for promoting development. J Human Devel and Capabilities I4(3), 323-40. 
Bhutta, Z. A. and R. E. Black (2013), Global maternal, newborn, and child health-so near and yet so far. N Engl J Med 369 (23), 222635.

Billari, Francesco and Alexia Fürnkranz Prskawetz (2003), Agent-Based Computational Demography, Physica Verlag.

Billari, Francesco, Dimitar Philipov and Maria R. Testa (2005), The influence of attitudes, subjective norms and perceived behavioural control on union formation intentions. IUSSP Conference Tours (France).

Bonvalet, Catherine et Eva Lelièvre (dir. 20I2), De la famille à l'entourage. L'enquête biographies et entourage, INED, coll. " Grandes Enquêtes ».

Courgeau, Daniel (2007), Multilevel Synthesis.From the Group to the Individual. The Springer Series on Demographic Methods and Population Analysis, V. 18, 227 p.

Drèze, Jean and Amartya Sen (2013), An uncertain Glory. India and its contradictions. Allen Lane, Penguin Book, London.

Emirbayer, Mustafa and Ann Mische (1998), What is Agency? AJS 103(4): 962-1023.

Lesthaeghe, Ron (1995), The second demographic transition in western countries : an interpretation. In K. Oppenheim Mason and A.-M. Jensen: Gender and Family Change in Industrialized Countries, Oxford University Press, 17-62.

Lindenberg, Siegwart (1996), Continuities in the theory of social production function. In H.Ganzeboom and S.Lindenberg (eds): Verklarende Sociologie: Opstellen voor R. Whiple. Thela, Amsterdam.

Locoh, Thérèse et Zahia Ouadah-Bedidi (to be published), Du vin nouveau dans la vieille outre familiale : les Africaines en quête de nouveaux rapports de genre. Cahiers Québecois démographie 2014.

Nussbaum, Martha (2000), Women and Human
Development, Cambridge University Press, Cambridge.

Robeyns, Ingrid (2005), The Capability Approach- A theoretical survey, Journal of Human Development, vol 6, no I, 93-II4.

Sen, Amartya (1999), Development as Freedom.New York: Knopf Press.

Tabutin, Dominique, Catherine Gourbin et G. Beninguisse (2007), Surmortalité et santé des petites filles en Afrique. Tendances des années 1970 aux années 1990. Chapitre 5 in Locoh (ed) : Genre et sociétés en Afrique. Cahier INED 160.

United Nations (2013), The Millennium Development Goals Report 2013. New York. Van de Kaa, D. J. (1994), The Second Demographic Transition Revisited: Theories and Expectations. Pp. 8I-I26 in: G. C. N. Beets et al. (eds.). Population and Family in the Low Countries, Lisse, Zwets and Zeitlinger.

Waage, Jeff et al (2010), The MDGs: a crosssectoral analysis and principals for goal setting after 2015. The Lancet \& London Internat Dev Centre Commission. The Lancet 376, 991-1023.

Wilkinson, Richard and Kate Pickett (2009), The Spirit Level: Why More Equal Societies Almost Always Do Better. Allen Lane.

Woods, R. (2000), The demography of Victorian England and Wales. Cambridge; New York: Cambridge University Press.

Woods, R. (2003), Urban-rural mortality differentials: An unresolved debate. Population and Development Review 29 (I), 29-.

Yamin, Alicia Ely and Vanessa $M$ Boulanger (2013), Embedding sexual and reproductive health and rights in a transformational development framework: lessons learned from the MDG targets and indicators. Reproductive Health Matters 2 I (42):74-85. 
i The author thanks Allan Hill for his valuable suggestions and editing work, as well as useful comments from Enrica Chiappero-Martinetti and from Shridar Venkatapuram on a previous version.

ii For instance, in the Upper Swiss Alp valleys, the indigent emerged as a new category with the arrival of the train in the early $20^{\text {th }}$ century.

iii

http://www.unece.org/fileadmin/DAM/pau/icpd/C onference/Other documents/Report ICPD beyond 2014.pdf

iv The Multi-Dimensional Poverty Index (MPI) is considering multiple deprivations across the same three dimensions as the HDI and shows the number of people who are multidimensionally poor (suffering deprivations in $33 \%$ of weighted indicators). (Human Development Report 2013, http://hdr.undp.org/en/statistics/mpi)

$\checkmark$ Women who agree that a husband is justified in beating his wife under a series of circumstances: wife burns the food, wife argues with him, wife goes out without telling him, wife neglects the children, and wife refuses to have sex with him.

vi As underlined by Robeyns, this scheme has to be understood as a non-dynamic representation: it does not feature causal relationships but the direction of conditionalities : conversion factors are a contingent to endowments and functionings to Capabilities.

vii In the same way the use of contraception is considered for the former as a resource and the latter a means. 